\title{
Adverse prognostic impact of TGFB / T869C polymorphism in non-small-cell lung cancer
}

This article was published in the following Dove Press journal:

OncoTargets and Therapy

10 March 2017

Number of times this article has been viewed

\section{Yulan Sang' \\ Xin $\mathrm{Bi}^{1}$ \\ Yan $\mathrm{Liu}^{2}$ \\ Wei Zhang' \\ Dongjie Wang'}

'Department of Respiratory, The First Affiliated Hospital of Harbin Medical University, ${ }^{2}$ Department of Respiratory,

The Fourth Hospital of Harbin,

Harbin, People's Republic of China
Correspondence: Wei Zhang Department of Respiratory, The First Affiliated Hospital of Harbin Medical University, \#23, Youzheng Street, Nangang District, Harbin I50086, Heilongjiang Province, People's Republic of China

Tel/fax +86 45I 85556000

Email drzhanghuge@।26.com
Abstract: Previously, several polymorphisms in TGFB1 have been identified in non-small-cell lung cancer (NSCLC), and the variants, C-509T, T869C, and G915C, have been demonstrated to associate with higher circulating levels of TGF- $\beta 1$. However, little is known about the prognostic value of TGF- $\beta 1$ polymorphisms in cancers. In this study, by genotyping the TGF- $\beta 1$ T869C polymorphism in a total of 261 patients with NSCLC using DNA from blood lymphocytes, we first found that NSCLC patients, especially those with allele $\mathrm{C}$ carriers, had significantly higher serum TGF- $\beta 1$ levels than healthy individuals. By using chi-square $\left(\chi^{2}\right)$ test and Fisher's exact test, we noticed that TC/CC genotypes were positively correlated with smoking, clinical TNM stage, lymph node, and distant metastasis in NSCLC patients. Kaplan-Meier analysis showed that patients with TT genotype had a better overall survival than the allele $\mathrm{C}$ carriers $(\mathrm{TC}+\mathrm{CC})$. Finally, multivariate analysis confirmed histology, lymph node, and distant metastasis but not T869C polymorphism as independent prognostic factors for NSCLC. Taken together, our data, as a proof of principle, suggest that T869C polymorphism in TGFB1 may act as a genetic modifier in NSCLC progression and a promising prognostic marker of survival in NSCLC patients.

Keywords: genotype and multivariate analysis, single-nucleotide polymorphisms, prognosis

\section{Introduction}

Lung cancer is a leading cause of cancer-related deaths worldwide. ${ }^{1}$ Nearly $75 \%-85 \%$ of patients with primary lung cancer are pathologically diagnosed with non-smallcell lung cancer (NSCLC). Despite intensive progress in preclinical and clinical studies, the prognosis of NSCLC is still poor, with a 5-year survival rate of only $15 \%{ }^{2,3}$ Currently, accumulating studies are underway to reveal the specific prognostic biomarkers that can predict the prognosis in patients with NSCLC. ${ }^{4}$ This may largely help to guide medical care of NSCLC patients, with either conventional chemotherapy or targeted therapies.

Genetic factors are critically involved in modulating cellular microenvironment and affecting carcinogenesis in a complicated manner. ${ }^{5,6}$ Single-nucleotide polymorphisms (SNPs) are the most common form of human genetic variation. Emerging evidence has demonstrated that SNPs affect gene expression and further increase the potential risk of cancer. ${ }^{7,8}$ Meanwhile, the prognostic value of SNPs has been revealed in multiple human cancers, including NSCLC. ${ }^{9-11}$

TGF- $\beta 1$ is a multifunctional cytokine that regulates many aspects of cellular function, including cellular proliferation, differentiation, migration, apoptosis, and immune surveillance. ${ }^{12}$ In cancers, it has been reported that TGF- $\beta 1$ acts as a tumor suppressor at early stages by inhibiting cell proliferation and as a tumor promoter at enhanced stages by facilitating tumor progression and metastasis. ${ }^{13}$ In lung cancer, several polymorphisms in the TGFB1 gene have been reported previously, including rs1800469, 
rs1800471, rs1982073, rs4803455, rs11466345, rs12983047, rs10417924, and rs10980942. ${ }^{14}$ Importantly, the association between TGFB1 polymorphisms and the risk of lung cancer has been well studied. ${ }^{15-18}$ However, limited knowledge is known about the prognostic value of these polymorphisms in lung cancer. In this study, we evaluated the prognostic value of an SNP of TGFB1 gene, rs1982073, which is also known as $\mathrm{T} 869 \mathrm{C}$, in a large-scale cohort.

\section{Materials and methods Study population}

A total of 261 NSCLC patients were recruited from The First Affiliated Hospital of Harbin Medical University between January 2006 and December 2012. All patients were diagnosed and histopathologically confirmed with NSCLC and without prior history of other cancers. None of the patients included in this study received radiotherapy, chemotherapy, hormone therapy, or other related antitumor therapies prior to surgery. Blood samples were collected from these patients for genotyping and detection of serum TGF- $\beta 1$ levels. Follow-ups were done every 3 months from the enrolled time until death or the last time of follow-up. The maximum follow-up time was 72 months, and the median follow-up time was 22.7 months. As a result, 213 patients with complete follow-ups were subjected to survival analysis. For certification of smoking, nonsmokers were defined as those who smoked $<1$ cigarette per day for $<1$ year; otherwise, they were considered as smokers. The control subjects were matched to the cancer cases on the basis of gender and age ( \pm 5 years). All the cases and the controls were ethnic Chinese, and they resided in Harbin City or in the surrounding regions.

This study was approved by the ethics committees of The First Affiliated Hospital of Harbin Medical University, and written informed consent was obtained from each individual for this study.

\section{TGFB / T869C genotyping}

Genomic DNA was extracted from blood samples using commercially available QIAamp DNA purification kit (Qiagen, Hilden, Germany), according to the manufacturer's instructions. The SNP T869C of the TGFB1 gene was determined by polymerase chain reaction-restriction fragment length polymorphism (PCRRFLP) using primers 5'-TATGAGGATGTGGTGCGTGT-3' (forward) and 5'-TGGGGTGGTGTTTACGTGATG-3' (reverse). The PCR was performed in a GeneAmp PCR system 9700 (Applied Biosystems, San Francisco, CA, USA) thermal cycler. Each PCR amplification reaction was conducted in a total volume of $25 \mu \mathrm{L}$. The reaction mixture included $50 \mathrm{ng}$ genomic DNA, $2.5 \mu \mathrm{M} \mathrm{MgCl}_{2}, 200 \mu \mathrm{M}$ dNTPs, 1 unit of
Taq polymerase (Qiagen), and $200 \mu \mathrm{M}$ primers. The PCR amplification consisted of a preliminary denaturation at $95^{\circ} \mathrm{C}$ for $10 \mathrm{~min}$, followed by 45 cycles of denaturation at $95^{\circ} \mathrm{C}$ for $15 \mathrm{~s}$ and annealing at $61^{\circ} \mathrm{C}$ for $1 \mathrm{~min}$. Genotyping results and statistical analyses were determined independently by two authors in a blinded manner.

\section{Enzyme-linked immunosorbent assay (ELISA) analysis of serum TGF- $\beta$ I levels}

After centrifuging blood samples, serum samples were obtained and stored frozen at $-70^{\circ} \mathrm{C}$ until used. Quantitative determination of the serum levels of TGF- $\beta 1$ was measured by a commercial ELISA kit (R\&D Systems, Minneapolis, MN, USA). Briefly, each serum sample or recombinant human TGF- $\beta 1$ was diluted and added to the microtiter plates precoated with TGF- $\beta$-soluble receptor type II and allowed to incubate overnight at $4^{\circ} \mathrm{C}$. After the incubation, the plate was washed three times with $1 \times$ Phosphate Buffered Saline add Tween-20 (PBS-T) and incubated with biotinylated antihuman TGF- $\beta 1$ for 2 hours at room temperature. Subsequently, horseradish peroxidase (HRP)-conjugated streptavidin was added to the plate and allowed to incubate for 30 minutes at room temperature. Color development was performed using a tetramethyl benzidine- $\mathrm{H}_{2} \mathrm{O}_{2}$ mixture and was terminated by $0.5 \mathrm{~mol} / \mathrm{L}$ sulfuric acid. Finally, the absorbance of each well at $490 \mathrm{~nm}$ was determined using a spectrophotometer.

\section{Statistical analysis}

All statistical analyses were performed using SPSS19.0 software (SPSS Company, Chicago, IL, USA). Hardy-Weinberg equilibrium (HWE) of the T869C polymorphism was tested by standard $\chi^{2}$ test. Survival time was calculated from the date of diagnosis to the date of death or to the last time of follow-up. Correlation of TGFB1 SNP with clinicopathological parameters in patients with NSCLC was evaluated by chi-square $\left(\chi^{2}\right)$ test or Fisher's exact test. The different survival times based on TGFB1 SNP were estimated by using the Kaplan-Meier method and compared by the logrank test. Univariate or multivariate Cox regression analysis was done to determine the prognostic factors of NSCLC prognosis by estimating the crude hazard ratios (HRs). $P$-values $<0.05$ were considered statistically significant.

\section{Results}

\section{TGFBI T869C polymorphism contributes to elevated serum TGF- $\beta$ I levels in NSCLC}

The demographics of the cases and controls enrolled in the current study are shown in Table 1. No significant differences 
Table I Characteristics of the study population

\begin{tabular}{lll}
\hline Variables & Cases, $\mathbf{n}(\%)$ & Controls, $\mathbf{n}(\%)$ \\
\hline Age (years) & & \\
$\geq 60$ & $133(51.0)$ & $49(51.6)$ \\
$<60$ & $128(49.0)$ & $46(48.4)$ \\
Gender & & \\
$\quad$ Male & $192(73.6)$ & $71(74.7)$ \\
Female & $69(26.4)$ & $24(25.3)$ \\
Smoking & & \\
Never & $89(34.1)$ & $39(41.1)$ \\
Ever & $172(65.9)$ & $56(58.9)$ \\
\hline
\end{tabular}

were found between the cases and controls regarding the age or gender distribution and smoking history. A total of 261 cases with NSCLC were enrolled in our study. The general clinical characteristics of the enrolled patients are summarized in Table 2. The genotype distributions of TGFB1 T869C polymorphism among the cases were in HWE. TGFB1 T869C polymorphism results in a Leu10Pro substitution in the hydrophobic core of signal peptide (Figure 1A). Notably, this transition has been associated with higher circulating TGF- $\beta 1$ levels, and this variant has been found

Table 2 Correlations between clinicopathological features and TGFBI T869C genotype frequencies in 26 I patients with NSCLC

\begin{tabular}{|c|c|c|c|c|}
\hline \multirow[t]{2}{*}{ Variables } & \multicolumn{4}{|c|}{ Genotypic frequencies } \\
\hline & TT (\%) & TC (\%) & CC (\%) & $P$-value \\
\hline Age (years) & & & & 0.828 \\
\hline$\geq 60$ & $69(26.4)$ & $45(17.3)$ & $19(7.3)$ & \\
\hline$<60$ & $62(23.7)$ & $45(17.3)$ & $21(8.0)$ & \\
\hline Gender & & & & 0.133 \\
\hline Male & 91 (34.9) & $73(28.0)$ & $28(10.7)$ & \\
\hline Female & $40(15.3)$ & $17(6.5)$ & $12(4.6)$ & \\
\hline Smoking & & & & 0.046 \\
\hline Never & $54(20.7)$ & $23(8.8)$ & $12(4.6)$ & \\
\hline Ever & $77(29.5)$ & $67(25.7)$ & $28(10.7)$ & \\
\hline Clinical stage & & & & 0.000 \\
\hline I & $49(18.8)$ & $7(2.7)$ & $4(1.5)$ & \\
\hline II & $19(7.3)$ & $14(5.4)$ & $4(1.5)$ & \\
\hline III & $47(18.0)$ & $48(18.4)$ & $8(3.1)$ & \\
\hline IV & $16(6.1)$ & $21(8.0)$ & $24(9.2)$ & \\
\hline Histology & & & & 0.610 \\
\hline Adenocarcinoma & $76(29.1)$ & $47(18.0)$ & $24(9.2)$ & \\
\hline Squamous cell & $42(16.1)$ & $36(13.8)$ & II (4.2) & \\
\hline Others $^{\mathrm{a}}$ & $13(5.0)$ & $7(2.7)$ & $5(1.9)$ & \\
\hline Lymph node & & & & 0.000 \\
\hline Positive & 7I (27.2) & $73(28.0)$ & $32(12.2)$ & \\
\hline Negative & $60(23.0)$ & $17(6.5)$ & $8(3.1)$ & \\
\hline Distant metastasis & & & & 0.000 \\
\hline Absent & II 5 (44.I) & $69(26.5)$ & $16(6.1)$ & \\
\hline Present & $16(6.1)$ & $21(8.0)$ & $24(9.2)$ & \\
\hline
\end{tabular}

Notes: ${ }^{a}$ Others include large cell, undifferentiated, and mixed-cell carcinomas. $P$-value $<0.05$ as statistically significant.

Abbreviation: NSCLC, non-small-cell lung cancer. to increase the risk of breast cancer. ${ }^{19}$ By ELISA analysis of the serum TGF- $\beta 1$ levels in 261 NSCLC patients and 95 healthy controls, we noticed that the mean serum TGF- $\beta 1$ value $(17.1 \pm 4.9 \mathrm{ng} / \mathrm{mL})$ was significantly higher than that of healthy controls (10.6 $\pm 2.6 \mathrm{ng} / \mathrm{mL}$; Figure 1B). Moreover, in both cases and controls, TGF- $\beta 1$ level was certainly increased in individuals with smoking history (Figure 1C). Specially, patients with TC or CC genotype showed increased serum TGF- $\beta 1$ levels compared with TT genotype carriers, indicating that $\mathrm{T} 869 \mathrm{C}$ polymorphism also certainly contributes to increased serum TGF- $\beta 1$ levels in NSCLC (Figure 1D).

\section{TGFBI T869C polymorphism predicts a poor prognosis in NSCLC patients}

To further determine the prognostic value of TGFB1 T869C polymorphism in NSCLC, the $\chi^{2}$ test was used to evaluate the correlation between T869C genotypes and corresponding patients' clinicopathological features, including age, gender, smoking, TNM stage, histology, lymph node metastasis, and distant metastasis. As shown in Table 2, allele $\mathrm{C}$ was positively associated with smoking history $(P=0.046)$, clinical stage $(P=0.000)$, lymph node metastasis $(P=0.000)$, and distant metastasis $(P=0.000)$, whereas no significant correlations were found in age, gender, and histology.

Then, by Kaplan-Meier analysis and log-rank test, we observed a different survival rate between different genotypes of TGFB1 T869C. The survival rate for NSCLC patients with TT or TC genotype was significantly lower than that for patients with $\mathrm{CC}$ genotype (Figure $2 \mathrm{~A}$ and $\mathrm{B}, P=0.023$ ). However, no remarkable difference in the survival rate was found between TT and TC genotype (Figure 2A).

Moreover, to identify the risk factors that correlated with the patients' outcome, we carried out univariate and multivariate analyses. The univariate Cox regression analyses showed that the genotype of TGFB1 T869C, histology, TNM stage, lymph node metastasis, and distant metastasis might be associated with the prognosis of NSCLC (Figure 3A). The multivariate Cox regression analysis revealed histology (risk ratio $[\mathrm{RR}]=1.008,95 \%$ confidence interval $[\mathrm{CI}]: 1.002-1.014$, $P=0.009$ ), lymph node metastasis ( $\mathrm{RR}=2.558,95 \%$ CI: $1.305-$ 5.014, $P=0.006)$, and distant metastasis $(\mathrm{RR}=1.817,95 \% \mathrm{CI}$ : 1.817-2.751, $P=0.004)$ as independent prognostic factors of the overall survival in patients with NSCLC (Figure 3B).

\section{Discussion}

In the present study, we demonstrated the prognostic value of TGFB 1 T869C polymorphisms in patients with NSCLCs. The results suggest that testing for the existence of these three genotypes in TGFB1 T869C may help to identify patient 
A

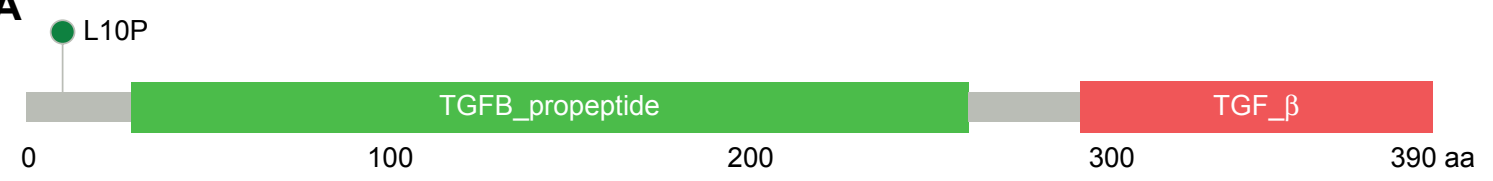

B

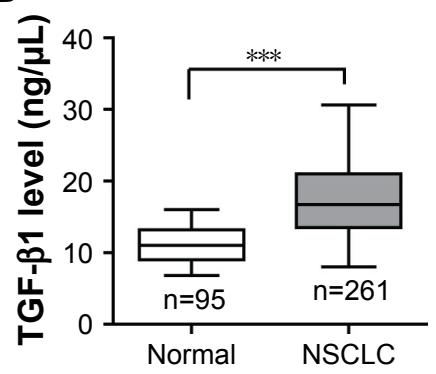

C

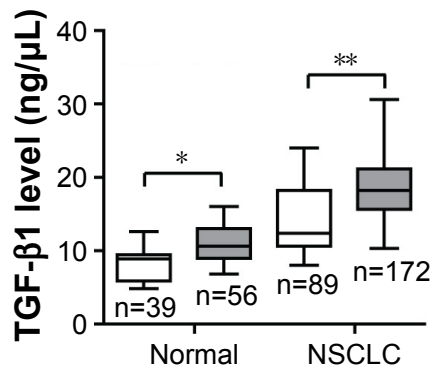

D

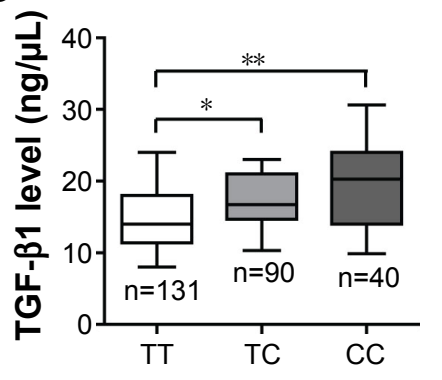

$\square$ Smoker $\square$ Nonsmoker

Figure I TGFBI T869C polymorphism contributes to elevated serum TGF- $\beta$ I level in NSCLC.

Notes: (A) The LeulOPro substitution resulted from TGFBI T869C polymorphism in the signal peptide of TGF- $\beta$ I protein. (B) The 3D structure of TGF- $\beta$ I protein. (C) The serum TGF- $\beta$ I level of NSCLC patients and healthy controls was tested by ELISA. (D) The serum TGF- $\beta$ I level among NSCLC patients with different genotypes. Data are shown as mean $\pm S D, P$-value was calculated by two-sided Student's $t$-test; $* P<0.05, * * P<0.0$, and $* * * P<0.00$ I.

Abbreviations: NSCLC, non-small-cell lung cancer; 3D, three-dimensional; ELISA, enzyme-linked immunosorbent assay; aa, amino acid.

subgroups at high risk of poor prognosis, thereby helping to make therapeutic decisions in the management of NSCLC. To the best of our knowledge, this is the first study to determine the prognostic effect of $T G F B 1$ polymorphism on the clinical outcomes of patients with NSCLC.

Previously, a large body of evidence has demonstrated that $T G F B 1$ polymorphisms contribute to lung cancer susceptibility. ${ }^{18,20}$ Several studies have also been conducted to determine the function of TGFB 1 polymorphisms in radiation pneumonia susceptibility in lung cancer patients. ${ }^{14,16}$ These findings suggest that several polymorphisms of TGFB1 gene could be used as genetic biomarkers for predicting the susceptibility of lung cancer. Notably, several studies have shown that C-509T, T869C, and G915C polymorphisms of $T G F B 1$ gene are associated with increased serum TGF- $\beta 1$ levels. ${ }^{18,21}$ Consistent with this notion, in this study, compared to healthy controls, patients with NSCLC had a higher serum TGF- $\beta 1$ level. Moreover, patients with a TC or CC genotype in the T869C polymorphism of TGFB1 gene had a higher TGF- $\beta 1$ level than those with a TT genotype.

Mutations in TGFB1 and its receptors, or associated downstream kinases of TGF- $\beta 1$ signaling, play key roles in the development of cancer. ${ }^{22}$ Most NSCLC patients exhibit resistance to the tumor-suppressive role of TGF- $\beta 1$
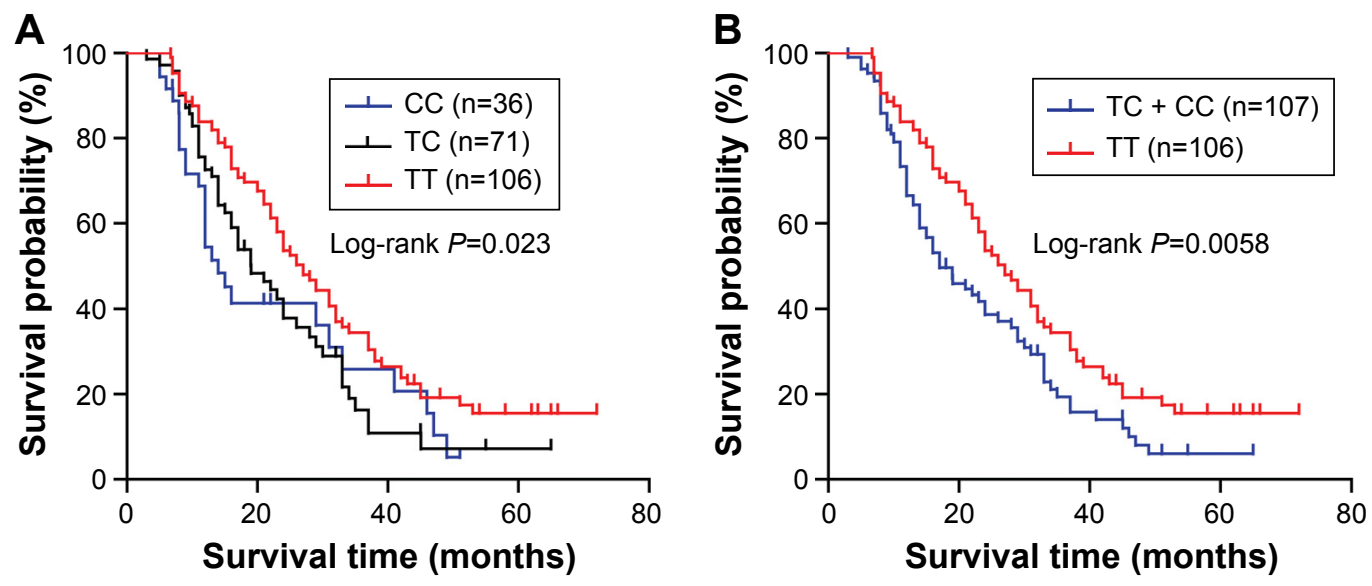

Figure 2 Kaplan-Meier curve of overall survival according to TGFBI T869C polymorphism in NSCLC.

Notes: (A) Survival analysis stratified by CC, TC and TT groups. (B) Survival analysis stratified by TC + CC and TT groups. $P$-value $<0.05$ was considered to be significant. Abbreviation: NSCLC, non-small-cell lung cancer. 


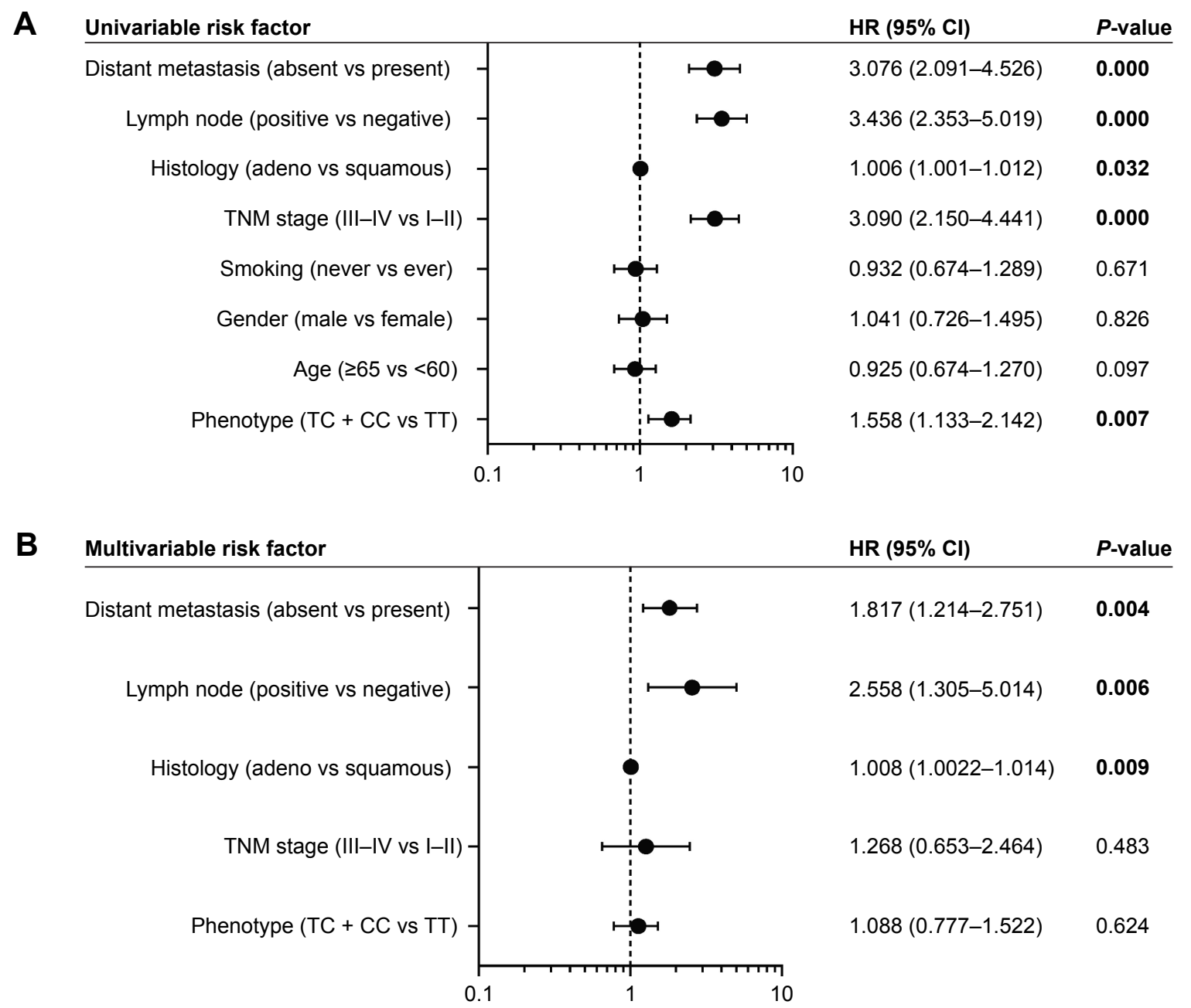

Figure 3 Prognostic factors in Cox proportional hazards model.

Notes: Univariate (A) and multivariable (B) analyses were performed to identify prognostic factors for NSCLC. All the bars correspond to $95 \%$ Cl. Bold numbers represent $P$-values with significant differences.

Abbreviations: NSCLC, non-small-cell lung cancer; $\mathrm{Cl}$, confidence interval; $\mathrm{HR}$, hazard ratio.

at advanced stage as a result of several alterations, such as mutations in SMAD4 and aberrant serum TGF- $\beta 1$ levels. ${ }^{12,23,24}$ TGF- $\beta 1$ acts as a tumor promoter through interactions with tumor microenvironment. It is widely reported that TGF- $\beta 1$ can suppress a repertoire of immune response, including cytotoxic T lymphocytes, macrophages, and natural killer cells. ${ }^{25}$ Therefore, we hypothesized that dysregulation of TGF- $\beta 1$ signaling induced by $\mathrm{T} 869 \mathrm{C}$ polymorphism of $T G F B 1$ gene might contribute to a poor prognosis in patients with NSCLC. In this study, we noticed that the genotypic distribution of T869C polymorphism in TGFB1 gene showed significant correlation with smoking history, clinical stage, lymph node metastasis, and distant metastasis. In addition, allele $\mathrm{C}$ of $T G F B 1$ (T869C) was associated with increased risk of tumor-related death, suggesting that SNP T869C of TGFB1 gene might be a potential prognostic marker for patients with NSCLC. However, the clear mechanisms underlying the unconfirmed roles of TGF- $\beta 1$ in NSCLC warrant further investigation.

Besides, several limitations in the current study must be specified. First, the healthy controls enrolled in our study were selected on the basis of gender and age, which might contribute to a bias. Second, replication in a validation cohort was not carried out. Finally, other SNPs (C-509T and G915C) of TGFB1 gene that contribute to increased TGF- $\beta 1$ levels should also be evaluated to test the common roles of those SNPs in NSCLC.

\section{Conclusion}

Our findings suggest that the T869C polymorphism of TGFB 1 gene was correlated with clinical progression of NSCLC patients and might be a genetic predictor for NSCLC prognosis. Furthermore, validation in a larger cohort and related functional characterizations are needed to confirm these observations. 


\section{Acknowledgment}

This work was supported by Education Department of Heilongjiang Province (12541550).

\section{Disclosure}

The authors report no conflicts of interest in this work.

\section{References}

1. Torre LA, Bray F, Siegel RL, Ferlay J, Lortet-Tieulent J, Jemal A. Global cancer statistics, 2012. CA Cancer J Clin. 2015;65(2):87-108.

2. Goldberg SB, Willers H, Heist RS. Multidisciplinary management of small cell lung cancer. Surg Oncol Clin N Am. 2013;22(2):329-343.

3. Spira A, Ettinger DS. Multidisciplinary management of lung cancer. N Engl J Medi. 2004;350(4):379-392.

4. Ludwig JA, Weinstein JN. Biomarkers in cancer staging, prognosis and treatment selection. Nat Rev Cancer. 2005;5(11):845-856.

5. Hill MJ. Interactions between genetic and environmental factors in colorectal carcinogenesis. Eur J Cancer Prev. 1997;6(1):1-2.

6. Langevin SM, Kratzke RA, Kelsey KT. Epigenetics of lung cancer. Transl Res. 2015;165(1):74-90.

7. Sigurdson AJ, Brenner AV, Roach JA, et al. Selected single-nucleotide polymorphisms in FOXE1, SERPINA5, FTO, EVPL, TICAM1 and SCARB1 are associated with papillary and follicular thyroid cancer risk: replication study in a German population. Carcinogenesis. 2016; 37(7):677-684.

8. MacPherson G, Healey CS, Teare MD, et al. Association of a common variant of the CASP8 gene with reduced risk of breast cancer. J Natl Cancer Inst. 2004;96(24):1866-1869.

9. Liu Y, Qing H, Su X, Wang C, Li Z, Liu S. Association of CD44 gene polymorphism with survival of NSCLC and risk of bone metastasis. Med Sci Monit. 2015;21:2694-2700.

10. Dong S, Guo AL, Chen ZH, et al. RRM1 single nucleotide polymorphism-37C-- $>$ A correlates with progression-free survival in NSCLC patients after gemcitabine-based chemotherapy. J Hematol Oncol. 2010;3:10.

11. Kim MJ, Kang HG, Lee SY, et al. AKT1 polymorphisms and survival of early stage non-small cell lung cancer. J Surg Oncol. 2012;105(2): $167-174$.
12. Blobe GC, Schiemann WP, Lodish HF. Role of transforming growth factor beta in human disease. N Engl J Med. 2000;342(18):1350-1358.

13. Elliott RL, Blobe GC. Role of transforming growth factor Beta in human cancer. J Clin Oncol. 2005;23(9):2078-2093.

14. Niu X, Li H, Chen Z, et al. A study of ethnic differences in TGFbetal gene polymorphisms and effects on the risk of radiation pneumonitis in non-small-cell lung cancer. J Thorac Oncol. 2012;7(11): 1668-1675.

15. Gonzalez-Zuloeta Ladd AM, Arias-Vasquez A, Siemes C, et al. Transforming-growth factor beta1 Leu10Pro polymorphism and breast cancer morbidity. Eur J Cancer. 2007;43(2):371-374.

16. He J, Deng L, Na F, Xue J, Gao H, Lu Y. The association between TGF-beta1 polymorphisms and radiation pneumonia in lung cancer patients treated with definitive radiotherapy: a meta-analysis. PLoS One. 2014;9(3):e91100.

17. Wang HB, Song WG, Liu HQ, Fang F, Xiao Y. Role of TGFB1 polymorphism in the development of metastatic brain tumors in non-small cell lung cancer patients. Genet Mol Res. 2015;14(2):3545-3550.

18. Kang HG, Chae MH, Park JM, et al. Polymorphisms in TGF-beta1 gene and the risk of lung cancer. Lung Cancer. 2006;52(1):1-7.

19. Dunning AM, Ellis PD, McBride S, et al. A transforming growth factorbeta 1 signal peptide variant increases secretion in vitro and is associated with increased incidence of invasive breast cancer. Cancer Res. 2003;63(10):2610-2615.

20. Teixeira AL, Araujo A, Coelho A, et al. Influence of TGFB1+869T $>$ C functional polymorphism in non-small cell lung cancer (NSCLC) risk. J Cancer Res Clin Oncol. 2011;137(3):435-439.

21. Grainger DJ, Heathcote K, Chiano M, et al. Genetic control of the circulating concentration of transforming growth factor type beta1. Hum Mol Genet. 1999;8(1):93-97.

22. Bierie B, Moses HL. Tumour microenvironment: TGFbeta: the molecular Jekyll and Hyde of cancer. Nat Rev Cancer. 2006;6(7):506-520.

23. Glick AB. TGFbeta1, back to the future: revisiting its role as a transforming growth factor. Cancer Biol Ther. 2004;3(3):276-283.

24. Nagatake $M$, Takagi $Y$, Osada $H$, et al. Somatic in vivo alterations of the DPC4 gene at 18q21 in human lung cancers. Cancer Res. 1996;56(12): 2718-2720.

25. Prud'homme GJ. Pathobiology of transforming growth factor beta in cancer, fibrosis and immunologic disease, and therapeutic considerations. Lab Invest. 2007;87(11):1077-1091.
OncoTargets and Therapy

\section{Publish your work in this journal}

OncoTargets and Therapy is an international, peer-reviewed, open access journal focusing on the pathological basis of all cancers, potential targets for therapy and treatment protocols employed to improve the management of cancer patients. The journal also focuses on the impact of management programs and new therapeutic agents and protocols on

\section{Dovepress}

patient perspectives such as quality of life, adherence and satisfaction. The manuscript management system is completely online and includes a very quick and fair peer-review system, which is all easy to use. Visit http://www.dovepress.com/testimonials.php to read real quotes from published authors. 